www.mbd.ase.ro

\title{
Understanding Voluntary Simplifiers in Bulgaria
}

\author{
Vanya Kraleva \\ University of Economics - Varna \\ vanya.kraleva@ue-varna.bg
}

\begin{abstract}
The notion of voluntary simplicity reflecting the rejection of growing consumeris m and materialism of our society and the orientation towards personal growth, ecological awareness and material simplicity instead gains more and more popularity in scientific literature. Even though in developed economies the first manifestations of this lifestyle date back to the 70s of the last decay, it is quite new to consumers in catching up countries like Bulgaria. The different economic and cultural background of these markets is a prerequisite for diverse motivational and behavioral models. Through qualitative research the current article examines the grounds for the adoption of voluntary simplicity values in Bulgaria and studies the changes in consumer behavior. The results from this study reveal important insights for marketers targeting this growing segment.
\end{abstract}

Key words: Voluntary simplicity, consumer behavior, anti-consumerism.

JEL classification: D12, M31.

\section{Introduction}

For many years the constant strive of humankind to achieve a better living fuels the pace of economic growth but ironically instead of satisfaction, it has brought a variety of concerns such as unequal distribution of world's wealth leading to social tension and boycotts, overconsumption and its environmental footprint, and an increasing number of diseases caused by stress or pollution. According to the latest Global Consumer Trends survey about $60 \%$ of people around the world are worried about climate change and more than $65 \%$ declare to be trying to have a positive impact on the environment (Holmes, 2016). In response to these global problems, many individual consumers are choosing to leave the "rat race" and live a less stressful, simpler and environmentally conscious life. This social movement known as voluntary simplicity started growing in the USA during the 70 s of the $\mathrm{XX}^{\text {th }}$ century and today an increasing number of people are influenced by its ideas (Goldberg, 1995, Peyer et al., 2017). Although there is an extensive body of literature on voluntary simplicity, the majority of studies covers affluent markets such as the USA (Elgin and Mitchell, 1977, Leonard-Barton and Rogers, 1980, Etzioni, 1998, Zavestoski, 2002, Huneke, 2005), the UK (Shaw and Newholm, 2002, Shaw and Moraes, 2009, Moraes et al., 2012) and Australia (Hamilton and Mail, 2003, Alexander and Ussher, 2012) and only a few give insights to less developed countries such as Poland (Zrałek, 2016), Czech Republic (Kala et al., 2016) and Turkey (Erdoðmup and Karapýnar, 2015). It is not surprising as voluntary simplicity is seen as a movement primarily of the well-off (Huneke, 2005, Etzioni, 1998, Craig-Lees and Hill, 2002). Anyway, recent studies refute this view and empirically prove that downshifting occurs across the income spectrum and might include low-income and blue-collar households (Zavestoski, 2002, Hamilton and Mail, 2003, Huneke, 2005). This raises grounds for testing the adoption of this lifestyle even in less developed countries where this phenomenon might be manifested far before reaching the point of material affluence. Given the limited research on this topic in catch-up countries, the aim of this paper is to examine the profile and the motivations of voluntary simplifiers in Bulgaria - a post-communist country with the lowest income in the EU. Being the first to tap into this field, the current study, uncovers important insights through in-depth interviews and a review of publically available online information in forums, blogs, and the social media. 


\section{Previous research on voluntary simplicity}

The term "voluntary simplicity" was first introduced by Richard Gregg in 1936 who described it as a mode of psychological hygiene that intends the avoidance of exterior clutter and the organization of life for a purpose (Gregg, 1936). Later it was analyzed and interpreted by numerous authors each one stressing on its different characteristics. Elgin and Mitchell (1977) state that "the essence of voluntary simplicity is living in a way that is outwardly simple and inwardly rich". Leonard-Barton and Rogers (1980) define it as "the degree to which an individual consciously chooses a way of life intended to maximize the individual's control over his/her own life". For Etzioni (1998) it is "the choice out of free will (...) to limit expenditures on consumer goods and services, and to cultivate non-materialistic sources of satisfaction and meaning". Zavestoski (2002) describes the practice of voluntary simplicity as "reducing clutter in one's life, eliminating burdensome time commitments, and creating peaceful personal space to enjoy life".

The values central to the movement consistent with cited definitions are: material simplicity, human scale, self-determination, ecological awareness and personal growth (Elgin and Mitchell, 1977). Material simplicity is about reducing all frills and luxury but it is not necessarily living cheaply as better quality might be sought. Human scale has to do with getting back to basics in living and working environments by focusing on the small things and the individual contribution to the whole. Self-determination reflects the desire for greater control over one's personal destiny manifested through consumption not dependent on any large and complex institutions. The ecological awareness acknowledges the interconnectedness and interdependence of people and resources and personal growth stands for a striving to clear away external clutter and explore the "inner life".

Many researches see the adoption of the voluntary simplicity lifestyle on a continuum. Etzioni (1998) observes different intensity in the manifestation of this phenomenon and proposes a typology of three types of voluntary simplicity: downshifters, strong simplifiers and holistic simplifiers (the Simple Living Movement). The first group is a rather moderate form of voluntary simplicity which according to Etzioni is "practiced by economically well-off and secure people who voluntarily give up some consumer goods (...), but basically maintain their rather rich and consumption-oriented lifestyle". The strong simplifiers being more dedicated often give up their well-paid jobs and status for less income in order to reduce the stress and have time for more meaningful things. The holistic simplifiers are at the extreme - they adjust their whole life patterns according to the ethos of voluntary simplicity which might include moving to the countryside or joining a community. Elgin and Mitchell (1977) recognize the following distinct categories: full voluntary simplifiers which constitute the active, leading edge of the movement and partial simplifiers which adhere only to some of the basic tenets and sympathizers who does not presently act on their sympathy towards voluntary simplicity. The rest of the population is categorized as indifferent, unaware, or opposed to voluntary simplic ity. Other classifications stress on simplifiers' motivation to change their lifestyle. These might include the three types distinguished by Leonard-Barton and Rogers (1980): conservers for whom frugal behavior is habitual as they have been brought up with a very strong prohibition against waste of all kinds; crusaders who have a strong sense of social responsibility and conformists who engage in voluntary simplicity behaviors for less well-defined reasons as well as the ethical simplifiers (Shaw and Newholm, 2002) and the sustainability-rooted anticonsumption for which voluntary simplicity is central (Seegebarth et al, 2016). Among the motivations of voluntary simplifiers are also environmental concerns, a direction towards healthier life, decluttering and self-sufficiency (Alexander and Ussher, 2012).

\section{Methodology for analyzing the voluntary simplicity movement in Bulgaria}

The review of popular definitions and classifications of adherents to the voluntary simplicity 
movement sets the grounds for analyzing the motivations and the consumer behavior of simplifiers which might be diverse in less affluent countries. It is argued here that even though Bulgaria is the poorest country in the EU, there are a growing number of people that adhere to the voluntary simplicity movement. The different economic backgrounds as well as the historical and societal events which Bulgarians have witnessed though have created altered motivations and consumption patterns that change the profile of the voluntary simplifier.

Trying to understand voluntary simplifiers in Bulgaria, we reviewed publicly available information on the topic in online forums, blogs, groups in the social network, etc. and conducted seven in-depth interviews. We started by googling either translated or transliterated keywords such as "anti-consumption", "downshifting", "minimalism", "simplicity life style", "self-sufficiency", etc. It was difficult to translate into Bulgarian the term "voluntary simplicity" and the search revealed that its simple transliteration is not familiar either. In different blogs and forums we found discussions on the practice of downshifting, selfsufficiency, anti-consumerism and minimalism. Several public groups in the social network that gather adherents to these ideas were also found. Other signs that the movement is present among Bulgarians are a number of special TV and radio broadcasts that focused on stories of simplifiers. Indicative is also the fact that the novel "Apparatus" (Georgiev, 2013) - an antiutopia of consumerist society - won the award "Novel of the Year 2013".

Using the social media and local communities, we contacted a selection of the most active participants who manifested a voluntary simplicity lifestyle and invited them to contribute to the research. Five out of a dozen reached answered and three of them agreed to be intervie wed. Those who took part in the research were further asked to provide contacts of acquaintances that adhere to the values of voluntary simplicity. Thus, using a snowballing approach, we managed to interview four women and three men. The interviews were conducted online or face-to-face where appropriate. Each session continued 60 to 90 minutes. The conversation was held in a semi-structured manner covering the questions of respondents' motivations to choose a simpler life, their values and day-to-day practices.

\section{Findings and discussion}

The profile of the participants in the research was quite different (Table 1). Two of them reside in small villages and the rest live in the city. Some of them are unemployed or have modest earnings, but there is also one respondent with a relatively high income. The age span covers the range from 32 to 64 years. Each of the interviewees had their own values toward life and their motivations to simplify varied. Some were guided by concerns for their health and wellbeing; others by environmental consciousness; still others were convinced that there is a conspiracy against humankind and overconsumption is its manifestation. What was common among them was that they all had realized that to be carried along with the crowd was ruinous and they were trying to reduce their negative impact over nature and the future generations.

\begin{tabular}{|l|l|l|l|}
\hline Interviewee & Age & Residence & Occupation \\
\hline Rositsa & 32 & Village & Housewife, part time translator \\
\hline Poli & 42 & City & Housewife, currently studying \\
\hline Dobromir & 42 & Village & Unemployed \\
\hline Dimitar & 39 & City & Software designer \\
\hline Tania & 53 & City & Kindergarten health-officer \\
\hline Miroslav & 47 & City & Radio engineer \\
\hline Zhana & 64 & City & Teacher, retired \\
\hline
\end{tabular}

Table 1. Profile of the interviewees

A 32-year-old housewife, for example was pushed to leave the city because she realized that she couldn't find happiness in the overcrowded city. She has moved to a small village where 
she raises her three children with the very modest income of a part-time translator and the help of her husband who runs a hardly dragging business.

Rositsa: "I have chosen to live in the countryside because I want to escape from all the drawbacks of civilization - the pollution, the stress, and the crowds. In the city everybody is rushed, it's like an ant-hill. This doesn't make any sense to me. I feel the health and the safety of my kids are endangered in such an environment. To be happy, you need to stay closer to the nature and to your inner world."

Other respondents also sympathize with the idea of moving out of the city but are held back by the difficulties related to it. Health care might not be provided, the public transport is irregular and it is hard to find a good job in the village and yet as stated by Dobromir, a spiritually devoted middle-aged man "... one still needs earnings to cover the monthly bills". He has always lived in the village house of his parents but he is forced to search for work in the city. Discussing the difficulties that check the movement back to less populated and uncivilized areas, some of the respondents talked about laying the foundations of a whole community where 20 to 50 families can build their own self-sufficient society. Quite idealistically this view revealed the longing for a new social order where people would cultivate their own land, grow vegetables and cattle and live in harmony with the nature. According to Tania, it could be a better solution than an ascetic escape.

Tania: "It is not possible to live totally isolated from society but one can create their own community with people who share the same ideas and goals. There are already a few eco communities like that but they are not functioning quite altruistically. It seems that they just reproduce the feudal systems from the near past."

Another reason to leave the city and create a new community of alternatively thinking people was expressed by Miroslav, who believes that it is the only way to liberate oneself from the chains of capitalism.

Miroslav: "Contemporary capitalism produces consumers, because all it needs is just consumers. It is all planned... the world is planned so that it can generate benefits for a handful of people. We should change this revolutionary by leaving the system, otherwise we are goners."

Common among the interviewees were also the anti-consumerist attitudes. Most of them were strong proponents of reducing our consumption to a level that minimizes our footprint to the environment. There was manifested a marked intolerance to unconscious and uncontrollable consumption which deprives the future generations from natural resources and pollutes the environment.

Poli: "One must be an idiot not to realize that overconsumption is killing us... Each family having at least two cars - this is devastating! All the garbage that is overfilling the containers in the city is a sign of redundancy. We have to change ourselves and our attitude towards the nature."

Coping strategies for reducing consumption and living more healthily may include riding a bike or walking instead of driving, buying environmentally friendly products, analyzing the necessity of an item before purchasing it, etc. Many of the interviewed were ready to invest their time in producing their own vegetables which was opposed to buying organic food because they distrusted retailers.

Zhana: "I won't buy organic food because it is too expensive and I don't believe that it is organic at all - it's just a commercial trick. The only way to eat healthily is to produce your own food. I have a yard in a nearby village where my husband and I grow some vegetables. I love the land and I am happy I have the chance to produce at least some of the food for my family."

Another important aspect of voluntary simplicity values that was approached in the intervie ws was the ethics of consumption stressed by Shaw and Newholmes (2002). Some of the 
www.mbd.ase.ro

respondents were carrying about the abuse of copyright and declared that they are ready to pay more for a product that was produced in an ethical manner.

Dimitar: "Once I watched a video of a special kite that was so much fun. I really liked that kite but it cost 300\$. Before I took the decision to buy it, I asked myself a hundred times whether I really needed it because I hate the clutter in my life. There were similar models that were less expensive but I decided to take the original one because those who invented it had invested a certain amount of resources and research to produce it while others just copied it. It's a kind of unethical to buy from those cloners."

The findings from the interviews prove to be consistent with previous research. Among the motivations to live a simpler life that were listed by the respondents were concerns about human impact over nature, spirituality, disagreement with the values of modern society, a desire to liberate the self from institutional and corporate hegemony, dissatisfaction with one's life and a search of inner growth, etc. A point of difference though is the fact that all of the interviewees declare to have always lived simply. None of them reported a real shift because they have never reached a peak from which to push themselves back. Some of them have intentionally moved to a simpler life but they can't really be described as downshifters like many simplifiers in more affluent countries. Even more it can be argued that the lack of financial resources has contributed to the formation of their simplicity values. Here is what one of the interviewees with currently high income shared:

Dimitar: "Probably my attitude to life is a consequence of living modestly as a child. When I was a boy I didn't have many toys and I really valued them. Pampered kids on the contrary can't take pleasure of all their belongings because they get bored very quickly. The act of acquiring something new has a very quick emotional effect and they want to experience it again and again. They get addicted to that feeling... I have never been tempting for glossy and expensive things. They are so demanding you need to use them all the time, to watch them over and take care. It's like in that old song "...the things you own, own you..." I think poverty has protected me from that all."

An interesting point to mention is also that none of the respondents were aware of the voluntary simplicity movement. They were even surprised but quite happy to know that a lot of people are turning to these ideas as it gives them hope that things will change. They declared to be sharing their beliefs with friends and acquaintances on every occasion as well.

\section{Conclusions}

The current article presents the results from a study of voluntary simplifiers in Bulgaria. What we argue based on these results is that voluntary simplicity is a state of the mind and it is not limited to the well-offs only. Voluntary simplicity is a personal choice which guides the individual through their life - whether to pursue a high-paid and high-status carrier and show off by means of consumption or to live simply with a modest income and more enriching relationships. All of the participants in the present study have declared that they have never been wealthy but, more importantly, they have never wanted to be. Instead, they have always been headed towards building their small world where love for their children and the entire nature matters most. Even if voluntary simplifiers intentionally reduce their consumption, they do not exit the market but only change the consumption pattern. A better understanding of their motivations and behavior in less explored low-income countries is important thus as they constitute an attractive target group for ecological products and alternative consumption options such as sharing (Peyer et al., 2017).

Being the first to examine voluntary simplifiers in Bulgaria, the present study reveals important insights to their profile and motivations but it also has some limitations. The qualitative 
www.mbd.ase.ro

approach that was undertaken allows the researcher to draw conclusions on a very restricted number of interviews that might bias the understanding of the phenomena under study. Another limitation stemming from the sample is that the simplifiers included were selected by snowballing which might also impose some bias.

Future empirical research may attempt to evaluate the adoption of the voluntary simplicity movement in Bulgaria and in other low-income countries. Quantitative research might be undertaken on the purchasing behavior of voluntary simplifiers as well as on different levels of adoption which might be compared with those in developed countries. A longitudinal approach that reveals the changes in the practice of simplicity lifestyles might also be valuable.

\section{Acknowledgments}

I would like to thank Valentina Yordanova for reading the draft and making valuable suggestions for improvement. I would also like to thank those who agreed to be intervie wed and told their stories. The author takes full responsibility for all views and interpretations.

\section{References}

ALEXANDER, S. \& USSHER, S. 2012. The Voluntary Simplicity Movement: A MultiNational Survey Analysis in Theoretical Context. Journal of Consumer Culture, 12, 6686.

CRAIG-LEES, M. \& HILL, C. 2002. Understanding Voluntary Simplifiers. Psychology and Marketing, 19, 187-210.

ELGIN, D. \& MITCHELL, A. 1977. Voluntary Simplicity. Co-Evolution Quarterly, 4-18.

ERDOĐMUP, Ý. \& KARAPÝNAR, E. 2015. Understanding Levels of Voluntary Simplicity in Turkey. Bogazici Journal, Review of Social, Economic and Administrative Studies, 29, $1-19$.

ETZIONI, A. 1998. Voluntary Simplicity: Characterization, Select Psychological Implications, and Societal Consequences. Journal of Economic Psychology, 619-643.

GEORGIEV, V. 2013. Apparatus, Ciela.

GOLDBERG, G. 1995. Choosing the Joys of a Simlified Life. New York Times.

GREGG, R. 1936. The Value of Voluntary Simplicity. Visva-Bharati Quarterly, reprinted in Manas (September 4, 1974).

HAMILTON, C. \& MAIL, E. 2003. Downshifting in Australia: A Sea-Change in the Pursuit of Happiness. Canberra: The Australia Institute.

HOLMES, L. 2016. New Lifestyles System Data: 2016 Global Consumer Trends Survey Results. Euromonitor International.

HUNEKE, M. E. 2005. The Face of the Un-Consumer: An Empirical Examination of the Practice of Voluntary Simplicity in the United States. Psychology and Marketing, 22, 527550.

KALA, L., GALCANOVA, L. \& PELIKAN, V. 2016. Dential Preferences in the Context of Voluntary Simple Lifestyles: What Motivates Contemporary Czech Simplifiers to Reside in the Countriside? Human Affairs-Postdisciplinary Humanities \& Social Sciences Quarterly, 26, 410-421.

LEONARD-BARTON, D. \& ROGERS, E. 1980. Voluntary Simplicity. Advances in Consumer Research, 7, 28-34.

MORAES, C., CARRIGAN, M. \& SZMIGIN, I. 2012. The Coherence of Inconsistencies: Attitude-Behaviour Gaps and New Consumption Communities. Journal of Marketing Management, 28, 103-128.

PEYER, M., BALDERJAHN, I., SEEGEBARTH, B. \& KLEMM, A. 2017. The Role of Sustainability in Profiling Voluntary Simplifiers. Journal of Business Research, 70, 37 43. 
SEEGEBARTH, B., PEYER, M., BALDERJAHN, I. \& WIEDMANN, K.-P. 2016. The Sustainability Roots of Anticonsumption Lifestyles and Initial Insights Regarding Their Effects on Consumers' Well-Being. Journal of Consumer Affairs, 50, 68-99.

SHAW, D. \& MORAES, C. 2009. Voluntary Simplicity: An Exploration of Market Interactions. International Journal of Consumer Studies, 33, 215-223.

SHAW, D. \& NEWHOLM, T. 2002. Voluntary Simplicity and the Ethics of Consumption. Psychology and Marketing, 19, 167-185.

ZAVESTOSKI, S. 2002. The Social-Psychological Bases of Anticonsumption Attitudes. Psychology and Marketing, 19, 149-165.

ZRAŁEK, J. 2016. Challenges of Sustainable Consumption: Voluntary Simplicity as a Social Movement. HANDEL WEWNECTRZNY, 361-371. 